\title{
Management of Pleural Empyema Using VATS with Jet-Lavage System
}

\author{
Eduard Kusch \\ Department of General, Visceral and Thoracic Surgery, Sankt Elisabeth Hospital, Guetersloh, Germany
}

Email address:

eduard.kusch@sankt-elisabeth-hospital.de

\section{To cite this article:}

Eduard Kusch. Management of Pleural Empyema Using VATS with Jet-Lavage System. Journal of Surgery. Vol. 6, No. 5, 2018 , pp. 135-139. doi: $10.11648 /$ j.js.20180605.15

Received: July 23, 2018; Accepted: September 21, 2018; Published: October 25, 2018

\begin{abstract}
Pleural empyema is a serious medical condition that is treated according to the stage. Because of the protracted course of this disease, treatment is very problematic in many cases. In general, pleural empyema therapy should be early and stage-appropriate. In stage I a combination of antibiotic therapy and drainage of the infected pleural effusion via a chest tube is performed. In stage II, proper drainage of loculated pleural empyema is only possible with operative intervention (Videoassisted thoracoscopy). The III stage of the disease results in pleural thickening which hinders lung expansion and restricts pulmonary function significantly. Therefore, early thoracotomy within 3 to 4 weeks is advised to prevent the formation of pleural thickening. In this study, pleural empyema in stage II is treated by means of video-assisted thoracoscopy with jet lavage The purpose of video-assisted thoracoscopy is the resolution of septations and removal of fibrin patches to allow the reexpansion of the lung. The Pulsavac Plus system is highly efficient through a variety of attachments coupled with a high flushing performance. In general, 3 accesses are required: 1 x $10 \mathrm{~mm}$ trocar for the camera, 1 x $15 \mathrm{~mm}$ trocar for the Pulsavac Plus system and 1 × $5 \mathrm{~mm}$ trocar for additional instruments. Between 1998 and 2015, a total of 311 patients were treated successfully with the above technique. Pulsed lavage irrigation provided efficient debridement by most patients and can, therefore, be considered as a useful alternative to the already established procedures. 90\% of patients (279/311) were successfully treated. In this paper, a not yet established surgical technique is presented (Video-assisted thoracoscopy with jet lavage), which offers an alternative to the conventional surgical techniques. The results are promising. The median hospital stay averaged 8 days. Randomized trials are still, of course, necessary to evaluate the effectiveness of the procedure.
\end{abstract}

Keywords: Pleural Empyema, Video Assisted Thoracoscopy, Jet-Lavage-Debridement

\section{Definition and Classification}

Pleural empyema is a collection of pus in the pleural space with an inflammatory reaction of the parietal and visceral pleura. The morphological course can be divided into 3 phases: exudative, fibrin purulent phase, and organization phase (Table
1). Based on the 3 phases, the American Thoracic Society has developed a classification system that is currently considered the standard classification of pleural empyema [1].

Table 1. Classification and stages of pleural empyema.

\begin{tabular}{lll}
\hline Stage & Phase & Characteristics \\
\hline 1 & exsudative Phase & Pleural thickening, increased permeability of the pleura, clear and sterile fluids, low cellular content \\
2 & fibrinopurulent Phase & Thick fibrin deposits, cloudy or purulent secretions \\
3 & Organisationphase & Invasion of fibroblasts, collagen deposits \\
\hline
\end{tabular}




\section{Etiology and Pathogenesis}

Pneumonia is the most common cause of pleural empyema. Approximately $40 \%$ of all bacterial pneumonia is associated with pleural effusion. The pathogen spectrum in pleural empyema depends on whether the pneumonia is anosocomial or community acquired. Streptococci Viridans [eg S. Milleri], S. aureus and mixed aerobic-anaerobic infections are frequently detectedin addition to the typical pathogen [S. pneumoniae]. In a recent multicentre British study, the spectrum of pathogens and the relative incidence of community acquired and nosocomial pleural empyema were investigated (Table 1).

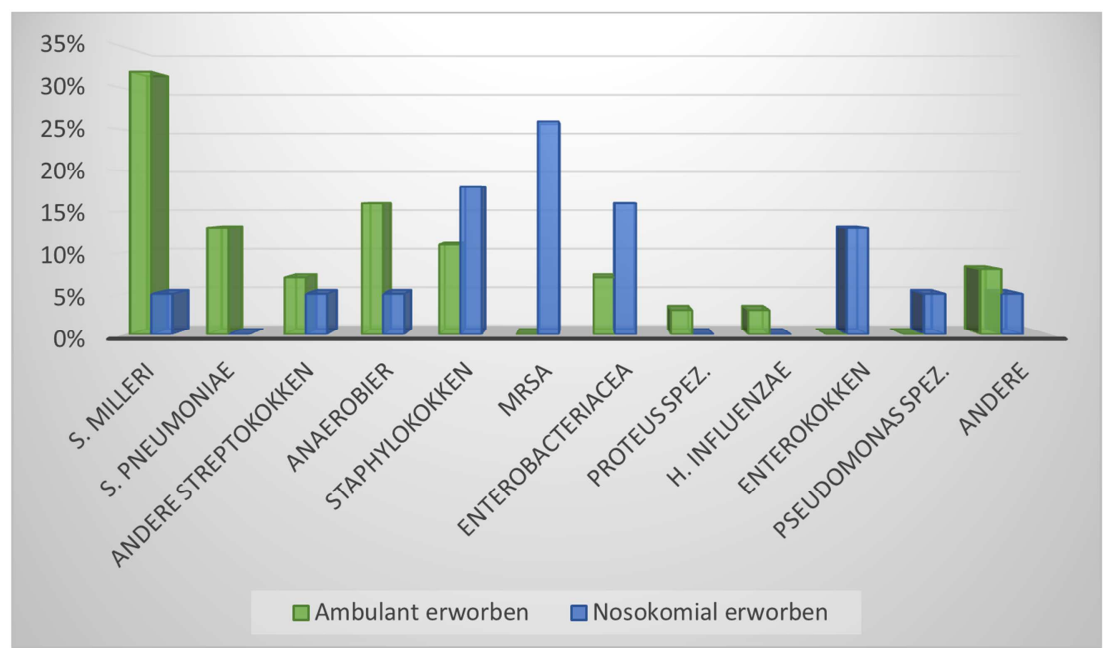

Figure 1. Pathogen spectrum and relative percentage in nosocomial andcommunity acquired pleural empyema [3]. Green: Communityaquired Blue: Nosocomial Infections

On the ground of pneumonia, a pleuritis sicca may first develop by spreading the inflammation to the visceral pleura. Subsequently, the increased capillary permeability due to the inflammation results in accumulation of fluid in the pleural space, which as a rule is initially sterile. Inadequate therapy or impairment of the immune system lead to the spread of infection, causing the exudate to become infected. The increased deposition of fibrin on the pleural surface may result in septations and localized adhesions. In the late phase, immigration of fibroblasts results in pleural thickening with septation of the effusion [4].

Apart from pneumonia as a causative factor, the following causes play a role: surgical interventions, traumas, pleural functions or abdominal infections (Figure 2).

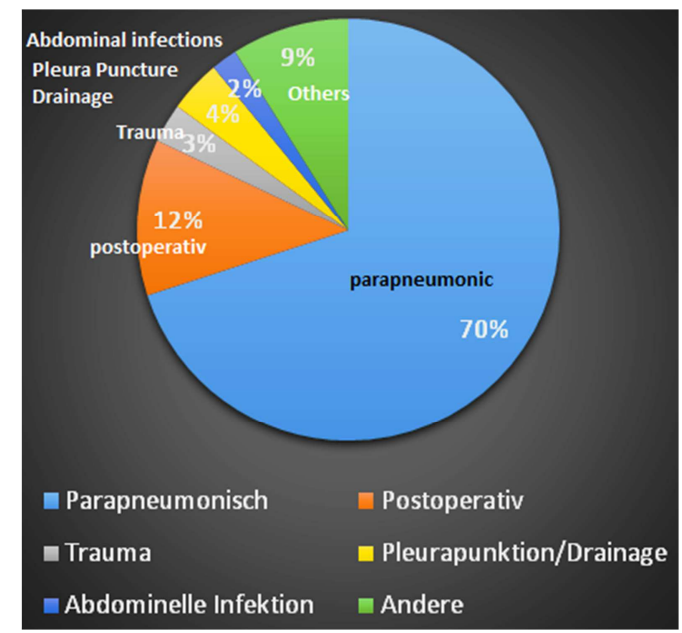

Figure 2. Causes of a pleural empyema.

\section{Diagnosis of Pleural Empyema}

The clinical picture is usually nonspecific and is associated with the underlying pathology. Pleural pain, dyspnea, and cough occur frequently in addition to general signs of infection such as fever and leukocytosis. Since these symptoms are not always present, it is recommended by suspicion of pleural inflammation to use imaging techniques and possibly effusion punctures. A quantity of approximately 200-300 ml of effusion can be demonstrated by means of conventional X-ray of the chest. X-ray can also demonstrate pneumonia as an underlying cause of the pleural effusion [8].

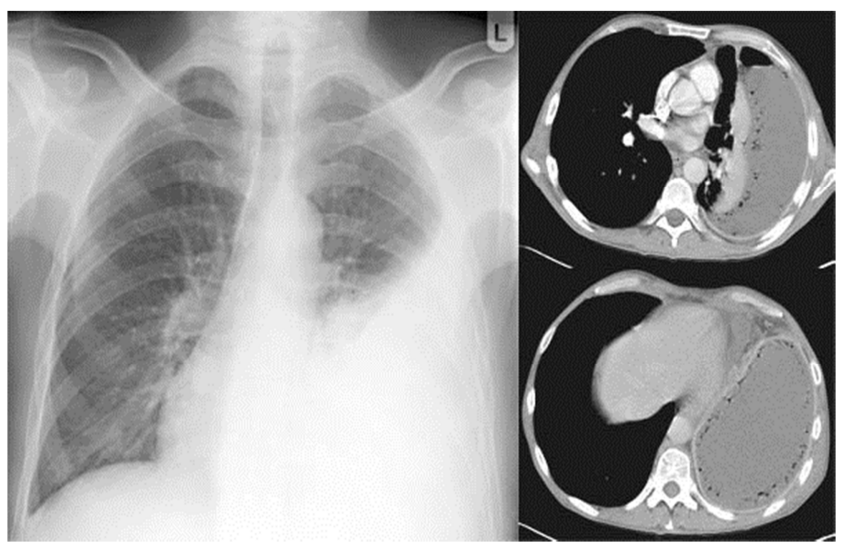

Figure 3. Thoracic CT.

With the help of Ultrasound, small pleural effusion, pleural thickening, and septations can also be seen. Computed tomography of the chest is used to diagnose poorly accessible 
effusions by Ultrasound (Figure 3), it also helps in the assessment of the respective pleural and parenchymal changes [13].

After the diagnosis of a pleural effusion is confirmed, it is recommended to perform aspiration of pleural fluid by a puncture. The sample is then analyzed microbiologically and biochemically.

The sample analysis serves not only to confirm the diagnosis but also enables the planning of the therapeutic procedure. Biochemical parameters, such as the determination of glucose or $\mathrm{LDH}$, and most importantly determination of the $\mathrm{pH}$ value, allow to estimate the degree of progression of the effusion. The importance of $\mathrm{pH}$ as a predictive value for the presence of a complicated effusion was shown in the meta-analysis by Heffner et al. [1]. For this purpose, a $\mathrm{pH}$ value of $<7.2$ was considered a limit, below which a drainage system was required. The results of this study were re-examined 5 years later by a group of experts from the American College of Chest Physicians. Thereafter, the insertion of a chest tube was recommended in the following categories:

(1) Patients with a large $>50 \%$ Hemithorax, septated effusion, or thickened pleura on CT scan.

(2) Patients with bacterial pleural infections, or with $\mathrm{pH}$ $<7.2$ from the sample.

(3) The presence of empyema.

\section{Therapeutic Strategies}

In general, management of pleural empyema should be early and stage-appropriate. In the transition from stage I to stage II, a combined irrigation/lysis therapy can be successful. (urokinase 150,000 IU in $100 \mathrm{ml} \mathrm{NaCl}$ per day / streptokinase $100,000 \mathrm{IU}$ in $100 \mathrm{ml} \mathrm{NaCl}$ per day, irrigation with $600-1000 \mathrm{ml}$ physiological solution up to 4 times daily) via a chest tube (24-28 Ch.) [2, 3, 5, 6, 16].

Stage II pleural empyema, however, VATS with debridement is the treatment of choice. The aim of the VATS is the breakdown of septations and removal of fibrin coatings to allow the re-expansion of the lung.

In this study, pleural empyema in stage II is managed by means of video-assisted thoracoscopy with jet lavage. The concept of jet lavage is widely used and has many applications, for example in orthopedics for the preparation of prosthetic implantation and in Re-do cases to minimize the risk of infections, as well as in traumatology for primary or secondary surgical wound care. In this study, the effectiveness of VATS with jet lavage is evaluated in patients with stage II pleural empyema [2, 5, 7].

There is little data in the current literature regarding the efficacy of pulsed pressure irrigation system in the treatment of pleural empyema. In the study published in 2010 by $\mathrm{H}$. Nakamura et al. [2], 31 patients were treated with VATS and jet lavage. The study included 31 patients, 26 male and 5 female, with a mean age of 60.5 years. The majority (26) were in stage II (fibrinopurulent phase), 2 in stage I (exudative phase) and the rest in the organization phase. Two types of pulsed pressure irrigation systems were used, Pulsavac plus and Interpulse. VATS was performed to remove the fibrinous deposits and to decorticate the thickened pleura followed by jet lavage to debride the necrotic tissue and fibrin deposits. In the end, chest tubes were inserted [9, 10, 14].

Debridement through jet lavage was successful in all patients. Revision with thoracotomy was required only in one patient, in the others, there was a significant clinical improvement despite the comorbidities, chest tubes removal was possible with an average of 6 days. The median hospital stay was 19 days. In the long term, no disease-related mortalities were documented $[11,12]$.

In this study, the concept of VATS with jet lavage was used to treat patients with stage II pleural empyema. The system we used was the Pulsavac Plus system (Figure 4). The pulse rate was set to $15-30 / \mathrm{sec}$ and a continuous flow rate to $1.6 \mathrm{ml} / \mathrm{min}$. The maximum pressure was $4.218 \mathrm{~kg} / \mathrm{cm}^{2}$.

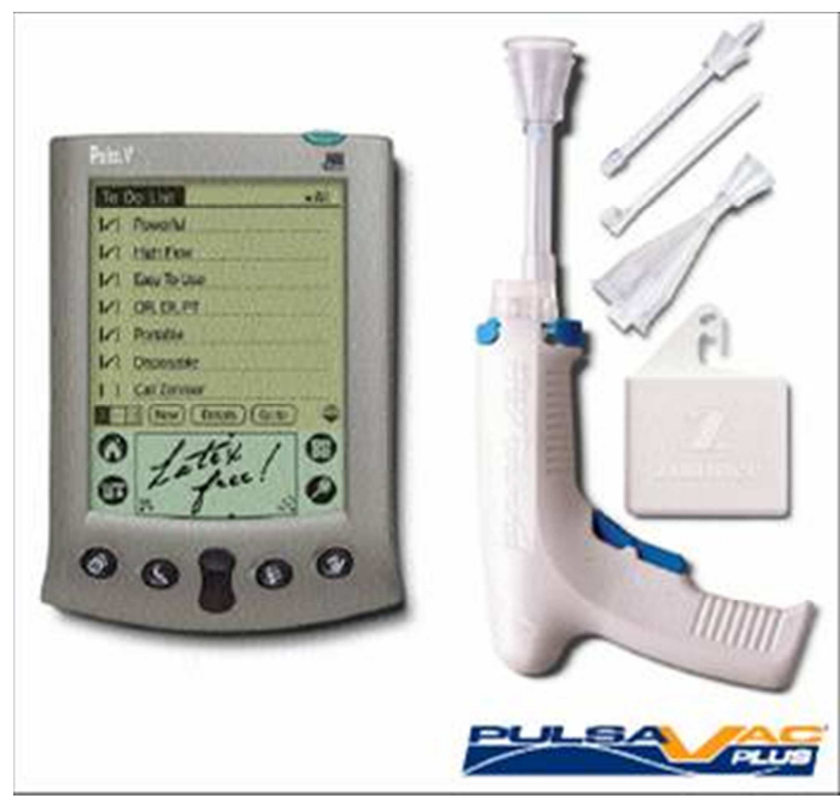

Figure 4. PulsavacPlus System.

The Pulsavac Plus system is highly efficient through a variety of attachments coupled with a high flushing performance. At the same time, the irrigation fluids are sucked out via a second channel, so that the operating field remains relatively clean and dry. Due to the high irrigation volume reduction in the number of germs can be achieved.

The already proven benefits of minimally invasive surgery also apply for VATS. It is associated with faster postoperative recovery, shorter hospital stay, and less postoperative pain. VATS is also suitable in patients with limited lung reserve because of lower lung impairment in contrast to the impairment caused by thoracotomy. As a rule, 3 small incisions are usually required: $10 \mathrm{~mm}$ for the camera, one for the forceps and the third for additional instruments. VATS basic instrumentation includes an endoscopic camera, 2 forceps, laparoscopic scissors, conventional long scissors, and suction-irrigation. 
Indications for performing a video-assisted thoracoscopy include:

(1) Pleural disease (pleural effusion, inflammation, malignancies).

(2) Mediastinal masses (lymphoma, lymph node metastases, sarcoidosis).

(3) Parenchymal Diseases (Interstitial Diseases, Peripheral Lung lesions).

(4) Pericardial diseases (effusion, biopsy).

(5) Staging of malignancies (lung cancer, esophageal cancer).

In this study, 311 patients were treated by VATS and jet lavage over a period of 16 years (1.06.1998 to 1.03.2015), 203 male and 108 female (Figure 5). All patients were stage II pleural empyema, $90 \%$ of the patients (279/311) were successfully treated, the median hospital stay was 8 days.

Although the concept of VATS with jet lavage is still not well-established procedure, data in this study showed excellent results, so that treatment with pulsed pressure lavage in stage II pleural empyema could be a good alternative to standard procedures. Randomized studies are of course necessary to evaluate the efficiency of the therapy procedure.

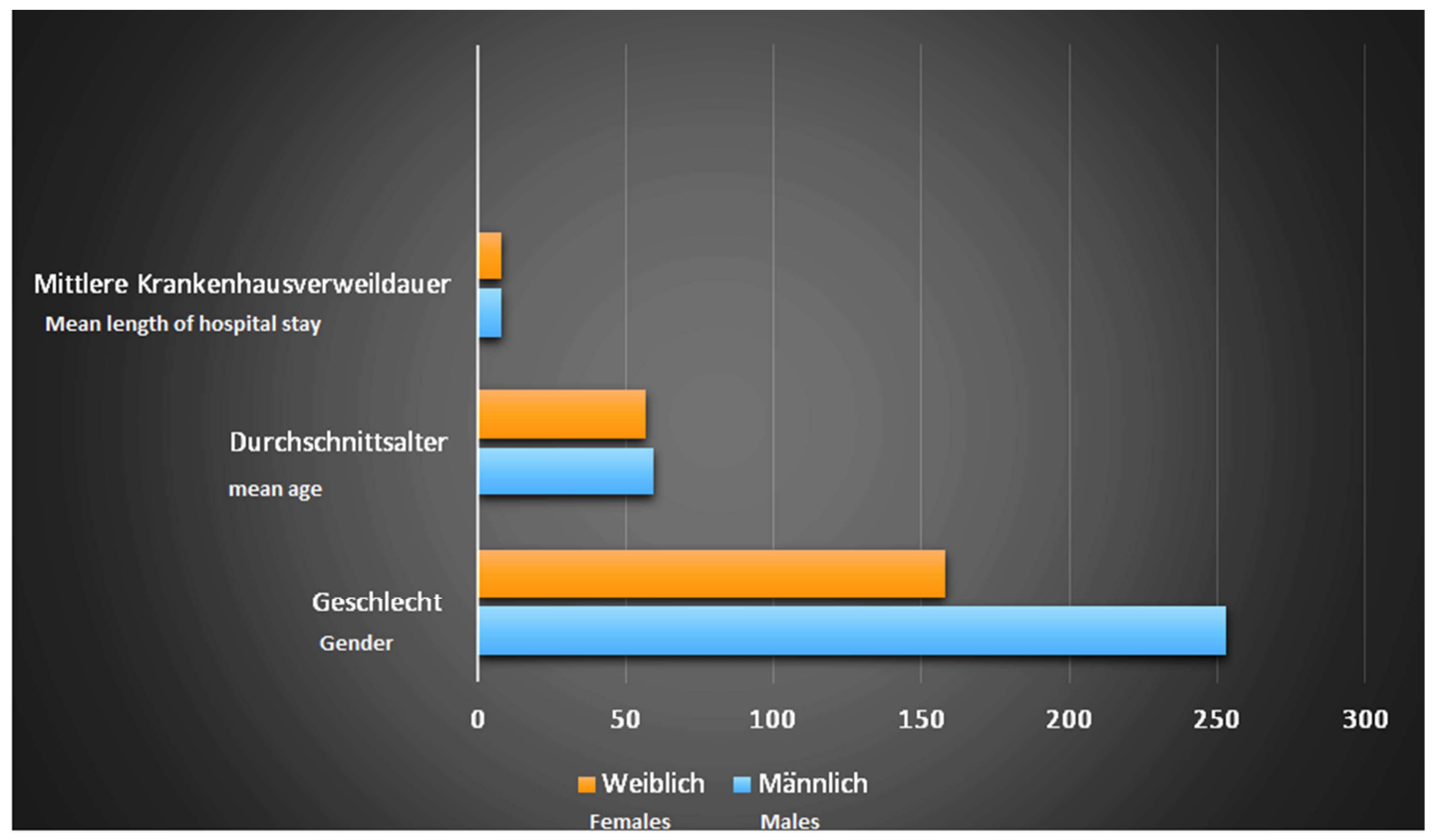

Figure 5. Mean length of hospital stay, mean age and gender of treated patients.

\section{Summary}

311 patients with acute thoracic empyema (Stage 2) were treated during the period from June 1998 through March 2015 with VATS using pulsed lavage irrigation (Pulsavac plus system). There were 203 men and 108 women, VATS with debridement and pulsed lavage irrigation were used to treat pleural empyema in Stage 2, pulse frequency was set to $15-30 / \mathrm{sec}$, and the flow-rate continuous to $1.6 \mathrm{ml} / \mathrm{min}$, the Maximum pressure was set to $4.218 \mathrm{~kg} / \mathrm{cm}^{2}, 90 \%$ of the patients were successfully treated, median postoperative hospital stay was 8 days. Pulsed lavage irrigation provided efficient debridement by most patients and can, therefore, be considered as a useful alternative to the already established procedures [15].

\section{References}

[1] Heffner JE, Brown LK, Barbieri C, DeLeo JM. Pleural fluid chemical analysis in parapneumonic effusions. A metaanalysis.Am J RespirCrit Care Med 1995; 151: 1700-1708.
[2] Nakamura H, Taniguchi Y, Miwa K, Adachi Y, Fujioka S, Haruki T. Surgical outcome of video-assisted thoracic surgery for acute thoracic empyema using pulsed lavage irrigation, Gen Thorac Cardiovasc Surg 2010; 58: 126-130.

[3] Maskell NA, Davies CW, Jones E. The characteristics of 300 patients participating in the MRC/BTS multicentre intrapleural streptokinase vs. placebo trial. Presented at the American Thoracic Society Meeting, Atlanta (GA); 2002.

[4] Maskell NA, Davies RJO. Effusions from parapneumonic infection and empyema. In: Light RW, Lee YCG, editors. Textbook of pleural diseases. London: Arnold; 2003. pp. 310-328.

[5] Klopp M,Pfannschmidt J,Dienemann H. Behandlung des Pleuraempyems. Chirurg 2008.

[6] Kolditz M, Höffken G. Management des parapneumonischen Ergusses und des Pleuraempyems. Pneumologe 2008.

[7] Lesser T. Minimal-invasive Thoraxchirurgie. Pneumologe 2008.

[8] Hamm H. Pleuraerguss: Rationale Diagnostik und Therapie. Pneumologe 2007.

[9] Solaini L, Prusciano F, Bagioni P. Video-assisted thoracic surgery in the treatment of pleuralempyema. SurgEndosc 2007; 21:280-284. 
[10] Kern L, Brutsche MH.Behandlung des Pleuraempyems mittels internistischer Thorakoskopie.Pneumologe 2010.

[11] Busk H, Huth C, Schreiber J.Chirurgie bei nichtonkologischen entzündlichen Thoraxerkrankungen. Pneumologe 2010.

[12] Luh SP, Hsu GJ, Cheng-Ren C. Complicated parapneumonic effusion and empyema: pleural decortication and videoassisted thoracic surgery. Curr Infect Dis Rep 2008; 10:236240.

[13] TasciS, Ewig S, Lüderitz B. Diagnose und Therapie von parapneumonischen Pleuraergüssen und Empyemen. Dtsch Arztebl 2004; 101: A-638 / B-532 / C-521.
[14] Bergmann T, Bölükbas S, Beqiri S, Schirren J. Diagnostische videoassistierte Thorakoskopie. Chirurg 2006.

[15] Tasci $\mathrm{S}$ et al. Langzeitergebnisse der intrapleuralen Fibrinolytikatherapie komplizierter parapneumonischer Pleuraergüsse und Empyeme über kleinlumige Katheter. Medizinische Klinik 2005; Volume 100: pp 181-185.

[16] Rahman NM, Maskell NA, West A et al. Intrapleural use of tissue plasminogen activator and DNase in pleural infection. $\mathrm{N}$ Engl J Med. 2011; 365: 518-526. 